\title{
Obituary
}

\section{PIET VAN DER LOON (7 April 1920-22 May 2002)}

The loss of Piet van der Loon, Emeritus Professor of Chinese, Oxford University, will be felt by all with any awareness of the field of Sinology. His breadth of interest in the oral and written traditions of Chinese culture led him to explore intricate questions behind the transmission of texts and performative arts alike, questions that he alone had the training and capacity to pursue in depth. He was one of those rare scholars who had the ability and energy to pursue research in the field as well as in the library. Piet was utterly at home in both, reveling in the way a close reading of texts and intensive fieldwork served as complements to each other. He inspired many to follow his example. His publications will continue to inspire for many generations to come. He leaves behind his wife and academic partner of fifty-five years, Minnie, their two daughters, Tillie and Maaike, and six grandchildren, not to mention countless Sinologists forever in his debt.

In spite of increasing health problems in later years, Piet was always willing to entertain questions pertaining to textual authority and fieldwork alike. Failing health could not, moreover, prevent him from remaining active in pursuing projects dear to his heart. Although he had to content himself with work at the desk rather than in the field, Piet continued to write and produce critical editions according to standards too demanding for most to honor. His fortitude, patience, and dedication to scholarship also allowed him the leisure to continue in his role as guide to anyone seeking his advice, even as he lamented the vicissitudes of ill health. It would be folly to try to enumerate all the subjects on which his expertise made him such a valuable mentor. Readers are referred to a bilingual transcript of an interview conducted by a team of reporters from Taiwan at his home on Old Boars Hill in Oxford. It lists van der Loon's research interests as "folk religions and drama of Taiwan, Fukien and Kwangtung; Chinese bibliography and collation of printed editions" (Laura Li, "Long Bide: Shouhu Zhongguo minsu de Hanxue jia" [Piet van der Loon: Academic champion of Chinese folklore], trans. Peter Eberly, in Dang Xifang yujian Dongfang-Guoji Hanxue $y u$ Hanxue jia (yi) [When west meets east-international Sinology and Sinologists] edited by Wang Jiafeng and Li Guangzhen. Taibei: Sinorama Magazine, 1991, p. 111; first printed in Guanghua [Sinorama] 14[8] [May 1989]).

Born in Rotterdam, Piet van der Loon attended primary school in Franeker (Friesland). His father was a printer by profession until his premature death in 1930. The loss of his father placed many responsibilities on ten-year-old Piet. As the eldest of four sons, he ended up doing a great deal of work for his mother as she strove to keep her late husband's business in operation. At the age of fourteen, Piet passed a competitive examination and won a family scholarship that had been established for worthy descendants by an ancestor in the fourteenth century. The scholarship allowed him to enroll at the Gymnasium (i.e., grammar school) in Leeuwarden, capital of the province of Friesland. It also gave him the opportunity to take up the study of Chinese 
at Leiden University during the difficult years of 1939-46. He subsequently honored his Leiden mentor, J. J. L. Duyvendak, with a necrology.

His academic career was briefly interrupted in 1940, when he attended the Reserve Officers' Training School (Infantry). With the German occupation of the Netherlands in May of that very year, he cleverly devised a means to escape deportation to a work camp. This he did by managing to register as a Sinologist rather than as a student. His strategic choice of identity apparently spared him from arrest on more than one occasion. It was an identity he was to claim with pride throughout his lifetime. When German occupation forces closed Leiden University, Piet and Minnie met, as they both endeavored to keep up with their studies in private.

In 1947, shortly after the war, van der Loon became a research student under Professor Gustav Haloun at the University of Cambridge and took Minnie as his wife. Although they made England their home for the next fifty-five years, both continued to take pride in their Dutch heritage. By 1 January 1948, Piet gained appointment as Assistant Lecturer in Chinese at Cambridge. Less than two years later, on 1 October 1949, he took up the post of University Lecturer in Far Eastern History. He held this position for twenty-three years, with affiliation at King's College. In 1972, Piet was appointed Professor of Chinese at Oxford, with affiliation at University College. He retired fifteen years later, in 1987. His friend and successor as Professor of Chinese at Oxford, Glen Dudbridge, is the contributor of the anonymously printed obituary that appeared in the 28 May 2002 issue of The Times of London.

From the very beginning of his long academic career, Piet van der Loon selflessly and energetically lent his expertise to substantive collaborative undertakings in Chinese studies. What is now known as the European Association for Chinese Studies has its roots in the annual European Congresses of Chinese Studies (originally "Junior Sinologues") that began in 1948 under van der Loon's initiative. He also helped organize the publication of Occasional Papers of the European Association of Chinese Studies and served as one of its editors. In volume 2 of this publication, Piet contributed his edition of "Chu Wen: A Play for the Shadow Theatre," based on a collation of five manuscripts in a southern Min dialect. Demanding endeavors of this kind won his lifelong attention if not the appreciative audience he deserved.

Many years earlier at Cambridge, Piet took on the editorship of Revue Bibliograpbique de Sinologie. This annual compilation is dedicated to providing abstracts for all important books and articles published the preceding year in the field of Sinology. It soon proved to be indispensable to all serious scholars, especially for its introductions to the easily overlooked studies of Chinese and Japanese scholars. The first volume appeared in 1956, merely one year after Etienne Balazs suggested the need for such a publication. Balazs himself contributed a preface to the inaugural volume of $R B S$, applauding the indefatigable energy, tenacity, and abnegation of both van der Loon and his collaborator, Hope M. Wright, in their ability to enlist the cooperation of scholars across the globe. Piet edited the first three volumes and took the responsibility of selecting publications to be reviewed for the next three volumes. Dozens of his own entries may be found in these as well as in subsequent volumes issued under his successor as editor, Donald Holzman. These abstracts demonstrate above all Piet's outstanding ability to say the most of substance using the least of words. The same may also be said for the numerous abstracts contributed by Piet's wife, listed as M. C. van der Loon. Piet also took part in another ambitious bibliographic enterprise proposed by Balazs, A Sung Bibliography (Bibliographie des Sung). This contribution to the Sung Project was finally published under Yves Hervouet's editorship in 1978. 
As a connoisseur and collector of fine editions, Piet was well equipped to serve as adviser to those wise enough to seek his expertise on the history of the printed word in China. As Dudbridge writes in the obituary: "He systematically combed the libraries of Europe for details of early holdings in Chinese, and built his many discoveries into an unrivalled private index of early Chinese publishing." Piet also displayed a profound interest in the maintenance and enlargement of the collections of Chinese texts in the libraries of both Cambridge and Oxford. He served as Honorary Keeper of the Chinese Books in Cambridge Universiry Library for many years after his departure from Cambridge, overseeing acquisitions by assiduously combing not only booklists from Hong Kong and beyond but also bookshops in London. His effort in this regard for over forty years, according to Dudbridge, "leaves Cambridge University permanently in his debt." In a subsequent note appearing in the 17 June issue of the Times, Adrian Roberts, former librarian at the Bodleian, adds that van der Loon, upon assuming the Chair of Chinese at Oxford in 1972, convinced university authorities to fund the acquisition of newly available reprints of essential Chinese texts. The high quality of the Chinese collection at Oxford University thus also owes much to his influence.

Piet's first attempt to engage in fieldwork proved frustrating. He went to China on sabbatical in 1956-57, at a time when foreigners were kept under particularly close watch. Piet showed his resourcefulness when, according to Minnie (personal communication, 30 June 2002), "He borrowed a bicycle from the Dutch chargé d'affaires to explore Peking and visit bookshops; and later managed to travel in the country for three months, having escaped from his official 'companions.' "When travel became even more difficult in China, Piet turned his attention to communities of Chinese living outside the mainland. These field trips, which began in 1965, took him to Cambodia, Laos, Malaysia, Singapore, the Philippines, Thailand, Hong Kong, and Taiwan. It was within the Chinese communities of these sites that Piet sought to document traditional ritual and theatrical practices whose very survival on the mainland was in jeopardy. Along the way, he befriended numerous Taoist priests and was allowed to observe them in practice, as well as to photocopy texts and make recordings. He trained his eye and ear on all aspects of the requiem services, from acrobatics, dance, and music to Taoist ritual and miracle plays. Piet was truly a vanguard in what is now a much more active field of research.

With Mrs. van der Loon's support, Piet not only warmly welcomed visitors to their home but also remained unfailingly gracious in maintaining correspondence with all who sought his guidance. It was to their home on Old Boars Hill that many working on the Projet Tao-tsang made a pilgrimage for training. Piet dedicated hours of his time counselling contributors to this collaborative enterprise, a project initiated on 15 January 1979, with funding from the European Science Foundation. His own contribution to the project came in the form of his impeccably researched Taoist Books in the Libraries of the Sung Period: A Critical Study and Index (London: Ithaca Press, 1984).

At an age when many would have been content to sit in comfort at home, Piet took advantage of his retirement in 1987 to follow up on his fieldwork. To that end, he travelled to the mainland, Hainan, and Taiwan, participating in conferences as well as engaging in new research. Many of his discoveries helped substantiate the perceptive interpretations he had introduced years earlier, as represented by perhaps his most widely cited study, "Les origines rituelles du théâtre chinois." Piet also managed to help organize and participate in collaborative field research on Nuo ritual drama in China. Publication of this research is likewise owing to his active role on 
the editorial board of a new journal issued in Xinzhu (Taiwan), under the title Zhongguo Nuoxi: Nuo wenbua yanjiu tongxun (Chinese Nuo ritual drama: Research reports on Nuo culture).

Piet's keen interest in early woodcut printings also led him to encourage the publication of many rare texts in facsimile. Among publications of this sort that won his active support is the thirty-one-volume Zhongguo minjian xinyang ziliao buibian (Collection of resources on Chinese popular beliefs), edited by Wang Qiugui and Li Fengmao (Taibei: Taiwan xuesheng, 1989). Most recently, he sought to organize as well as train a team of editors to prepare for publication rare copies of scripts used by Minnan puppeteers. The last publication he saw to completion is a critical edition of the Quanqiang Mulian jiumu (Mulian saves his mother, a script in Quan[zhou] operatic mode), coedited with Shi Binghua (Taibai: Shi Hecheng jijin hui, 2001).

Although he was known to resist any effort to be honored with a festschrift, two volumes dedicated to Piet van der Loon are now in print. An issue of Asia Major, 3rd ser., 3(1)(1990), marking his seventieth birthday, includes contributions by eight colleagues from Canada, England, France, Germany, Holland, and Taiwan. It is unfortunate that Piet missed seeing the publication of Etbnography in China Today: A Critical Assessment of Methods and Results, edited by Daniel L. Overmyer (Taibei: Yuanliou Publication Company, 2002). The flyleaf of this collection of essays on contemporary studies of ritual and ritual theater in diverse Chinese communities reads: "This book is dedicated to Piet van der Loon, a pioneer in the study of Chinese ritual theatre." Plans are now underway, according to Glen Dudbridge, to establish a Piet van der Loon website, which will include Piet's own list of ritual recordings and a catalogue of his collection of books by David Helliwell, who is overseeing its transfer to the Bodleian Library. 